\title{
Population screening in a Druze community: the challenge and the reward
}

Tzipora C. Falik-Zaccai, MD ${ }^{1,2}$, Nechama Kfir, MSc $c^{1}$, Pnina Frenkel, MSc ${ }^{1}$, Cindy Cohen, MA ${ }^{1}$, Mary Tanus, BSc ${ }^{3}$, Hanna Mandel, $M D^{2,4}$, Shihab Shihab, $M D^{3}$, Siman Morkos, $M D^{5}$, Salameh Aaref, $M D^{5}$, Marshall L. Summar, $M D^{6}$, and Morad Khayat, $P h D^{1}$

\begin{abstract}
Purpose: The Druze community is characterized by consanguinity and endogamy, and by reluctance to genetic testing and technological interventions for the prevention of birth defects. Multiple patients with four rare and severe inborn errors of metabolism cerebrotendinous xanthomatosis, prolidase deficiency, argininosuccinate lyase deficiency, and carbamyl phosphate synthetase I deficiency were identified in an isolated Druze village in northern Israel. The aims of this study were to identify couples at risk for four inherited diseases, and to prevent birth defects in a community presenting religious and cultural obstacles to genetic testing. Methods: A genetic screening and counseling program in a high-risk community. Results: The 1425 residents who attended group genetic counseling sessions between 2003 and 2007 consented to genetic testing. We identified 217 carriers for either one or two disease causing mutations. High carrier frequencies for cerebrotendinous xanthomatosis, prolidase deficiency, argininosuccinate lyase deficiency, and carbamyl phosphate synthetase I deficiency were identified as 1:11, 1:21, 1:41, and 1:95, respectively. Fifty-eight percent (125) of the carriers' spouses agreed to genetic counseling and testing. Ten couples at risk for affected offspring were identified and offered prenatal genetic counseling and diagnosis. Conclusions: The genetic screening program, the first of its kind reported in a Druze community, was well received. We expect this program to increase awareness of genetic counseling, to contribute to disease prevention, and to serve as a model for other isolated communities. Genet Med 2008:10(12):903-909.
\end{abstract}

Key Words: argininosuccinate lyase deficiency, carbamyl phosphate synthetase I deficiency, cerebrotendinous xanthomatosis, population screening, prolidase deficiency

The Druze population comprises separate isolated communities in Syria, Lebanon, Jordan, and Israel. The 150,000 Druze in Israel reside in three distinct geographical regions: the Carmel, the Golan Heights, and the Galilee. Haplogroup analyses indicate particular isolation of the Galilee population. ${ }^{1}$ The practices of endogamy and consanguinity, and the prohibition of conversion have preserved isolation of the Druze communities. In studies conducted in Israel during 1990-1992, 53\% of the Druze women interviewed after giving birth were married to a relative, ${ }^{2}$ compared with $2.3 \%$ of Jewish women. ${ }^{3}$

A high inbreeding coefficient is a risk factor for birth defects and autosomal recessive (AR) disorders. ${ }^{4-7}$ Not surprisingly, the prenatal incidence in Israel for almost all major malforma-

From the ${ }^{1}$ Institute of Human Genetics, Western Galilee Hospital-Nahariya, Israel; ${ }^{2}$ Rappaport Faculty of Medicine, Technion, Israel Institute of Technology, Haifa, Israel; ${ }^{3}$ Israeli Ministry of Health, Akco district, Israel; ${ }^{4}$ Metabolic Unit, Rambam Medical Center, Haifa, Israel; ${ }^{5}$ Sherutei Briut Clalit, Western Galilee District, Israel; and ${ }^{6}$ Vanderbilt Univ Medical Ctr, Ctr Human Gen Res/Med Gen, Nashville, Tennessee.

Tzipora C. Falik Zaccai, MD, Institute of Human Genetics, Western Galilee Hospital, Naharia, P.O. Box 21, Naharia 22100, Israel. E-mail: Tzipora.Falik@naharia.health.gov.il.

Disclosure: The authors declare no conflict of interest.

Submitted for publication July 22, 2008.

Accepted for publication September 8, 2008.

DOI: 10.1097/GIM.0b013e31818d0e of tions is higher among Druze than Jews. ${ }^{8}$ The fact that terminating pregnancies of affected fetuses is much less common among Druze than Jews ${ }^{8}$ results in a difference in the rate of malformations between these populations that is even greater at birth than prenatally. For example, during 1991 and 2000 the rate of Down syndrome at birth was 2.4 times higher among Druze than Jews, and the rates for anencephaly and encephalocele were more than five times higher. ${ }^{8}$

Screening of high-risk populations has proven successful and cost effective for the prevention of life-limiting AR diseases such as Tay Sachs, cystic fibrosis, and Thalassemia. ${ }^{9-12}$ The ultimate goal of population screening is reduction in the incidence, morbidity, and mortality of birth defects and genetic disorders. The risk of disease, the availability of highly sensitive testing, and the benefit of early diagnosis are among the criteria for selecting genetic tests to be performed in particular subpopulations. Technological advances and population assimilation have enhanced the viability and benefit of pan-ethnic genetic testing. ${ }^{13}$ However, the screening of endogamous populations at high risk for identified diseases should still be a public concern. In 2002, the Israeli Ministry of Health launched a program to provide free of charge genetic screening to high-risk populations in Israel. ${ }^{14}$ Consequently, we and others ${ }^{15,16}$ set out to systematically screen isolated communities for severe genetic disorders with 
local disease prevalence rates exceeding 1 per 1000 live births and local carrier rates exceeding 1/15.

We describe herein the genetic screening program we implemented in an isolated Druze village in the Galilee, in northern Israel (Fig. 1). Founded more than 1000 years ago by a few nuclear families, this village currently has a population of 14,000 residents. Multiple patients for four rare inborn errors of metabolism (IEMs) have been identified there over the last 20 years: cerebrotendinous xanthomatosis (CTX), prolidase deficiency (PD), argininosuccinate lyase deficiency (ASLD), and carbamyl phosphate synthetase I deficiency (CPSD).

We report here the first genetic screening program implemented in a Druze community.

\section{MATERIALS AND METHODS}

\section{The four metabolic disorders screened}

Cerebrotendinous xanthomatosis

Cerebrotendinous xanthomatosis (CTX), OMIM \# 213700, is a lipid-storage disease characterized by infantile-onset diar- rhea, childhood-onset cataracts, adolescent-to-young adultonset tendon xanthomas, and adult-onset progressive neurologic dysfunction (dementia, psychiatric disturbances, pyramidal and/or cerebellar signs, and seizures). CYP27A1 is the only gene known to be associated with this disorder. A nonsense mutation, $355 \mathrm{delC}$ in exon 2 of the gene CYP27A1, was identified in 20 Israeli Druze CTX patients residing in the village described herein. ${ }^{17}$ Patients treated at the early asymptomatic stage with cenodeoxycholic acid (CDCA) do not suffer from the irreversible consequences of cholestanol and cholesterol depositions in multiple body organs. ${ }^{18}$

\section{Prolidase deficiency}

Prolidase deficiency (PD), OMIM \# 170100, is characterized by a highly variable phenotype, from no manifestation to severe progressive skin lesions, severe infections, respiratory abnormalities, and impaired cognitive development. ${ }^{19,20}$ Affected subjects excrete massive amounts of iminopeptides into the urine, these peptides being the substrate for the deficient enzyme, prolidase. Three affected individuals in this village

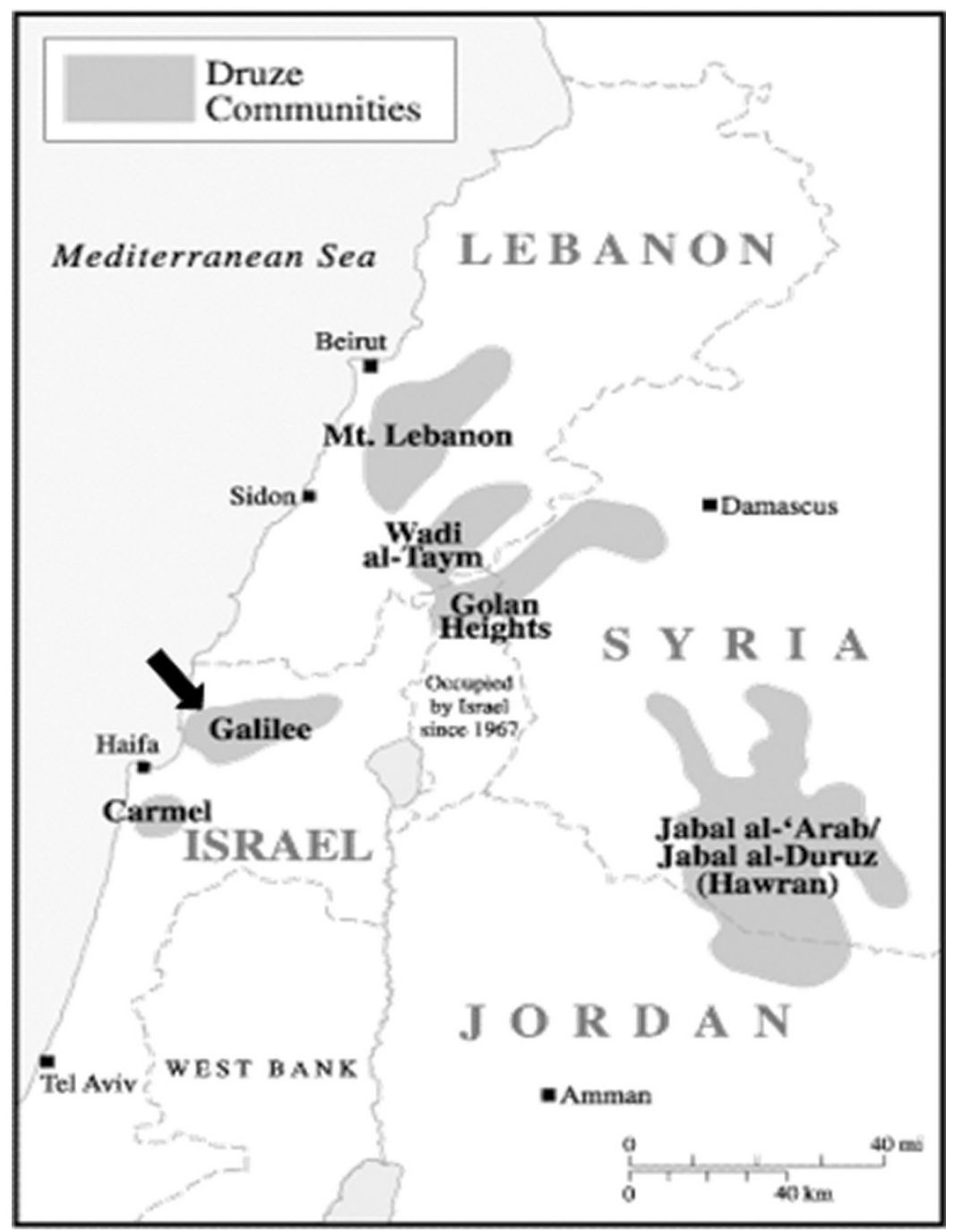

Fig. 1. A map of the Druze communities in the Middle East. The arrow indicates the Druze village, where the screening program took place. 
were found homozygous for the mutation c.605C $>\mathrm{T}$ $(\mathrm{S} 202 \mathrm{~F})^{20}$ in exon 8 of the PEPD gene.

Argininosuccinate lyase deficiency and carbamyl phosphate synthetase I deficiency

Argininosuccinate lyase deficiency (ASLD), OMIM \# 207900, and carbamyl phosphate synthetase I deficiency (CPSD), OMIM \# 237300, are noncurable IEMs involving the urea cycle. In cases of homozygous deficiency of ASLD or CPSD, hyperammonemia and irreversible severe brain damage occur. The causative mutations for ASLD or CPSD identified in the described village are fatal.

A nonsense mutation, c.346C $>\mathrm{T}$ (Q116X), in exon 4 of the gene $A S L,{ }^{21}$ was identified in five patients.

The CPS1 gene was sequenced using standard protocols searching for the causative mutation in the three patients identified in the village.

\section{Structure and process of the screening program}

In the first stage, from January 2003 until May 2005, we screened 1134 individuals for the four metabolic disorders described earlier. In May 2005, the Israeli Ministry of Health decided to cease the funding of genetic testing for CPSD and ASLD, due to the low number of carriers detected (the carrier frequency was $<1 / 15$, the cutoff point determined by the Israeli Ministry of Health). Consequently, during the period from June 2005 until December 2007, we screened 291 individuals for CTX and PD only.

The screening program consisted of the following:

1. A medical geneticist, genetic counselor, and genetic molecular biologist from the Institute of Human Genetics of the Western Galilee Hospital-Nahariya met with the family practitioners and nurses in the village to discuss the importance of the program and means of achieving maximum cooperation in the community. The prenatal clinic in the village was determined as the best place to approach women and couples of child-bearing age, the target population for the proposed screening.

2. The nurses invited to each meeting 15-25 women of childbearing age whose spouses originated from the same village. Each meeting comprised:

a. Group genetic counseling in Arabic, the local language (Fig. 2), including the following topics: the rationale of the screening program, the pathologies of the four tested metabolic disorders, heredity of recessive disorder, and the correlation between consanguineous marriages and the birth of children with genetic defects.

b. Private counseling, including intake on family medical history and the preparation of a three-generation pedigree, and an in-depth explanation about the significance of molecular testing and the informed consent process. Issues of privacy and high confidentiality were emphasized.

3. We extracted genomic DNA from 10-mL blood samples using a standard salting out method, and performed molecular tests to detect carriers for the four metabolic disorder causative mutations. Results were available within 3 weeks. Abnormal test results were reported at individual counseling sessions.

We invited the spouses of detected carriers for genetic counseling and molecular testing. Couples with both partners identified as carriers were invited for an additional genetic counsel-

\section{فحص "حامل/نافلة" لمرض ور اثي معيّن}

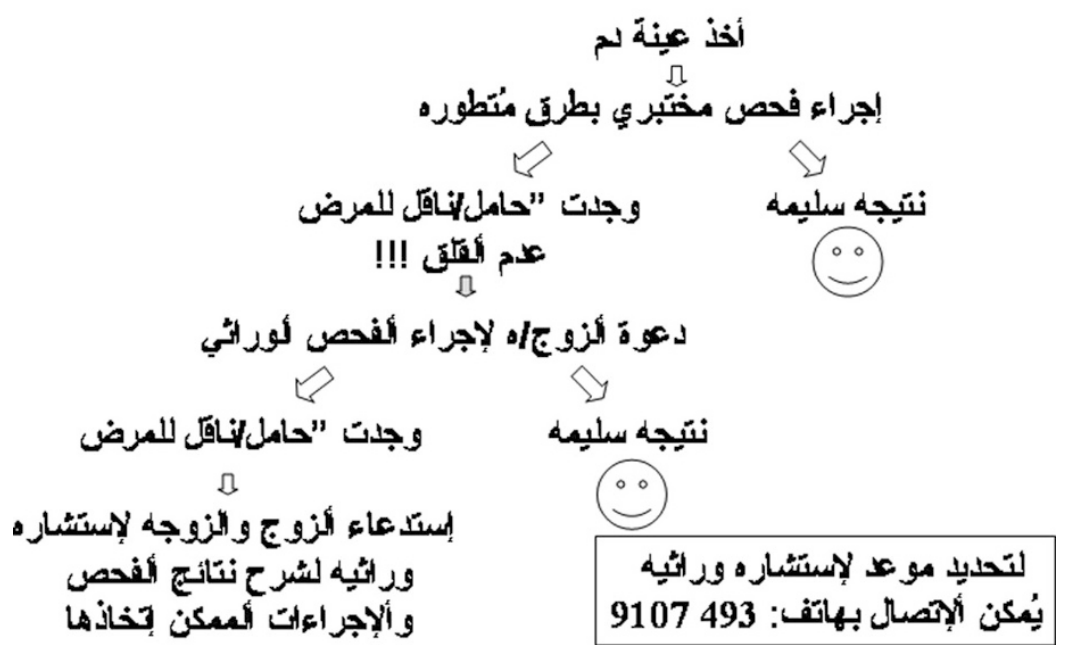

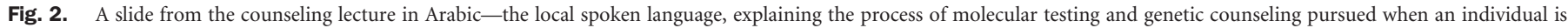
identified as a carrier. If the spouse is also a carrier then the couple is referred for genetic counseling regarding their options for prenatal diagnosis. 
ing session, in which they received more specific information about the particular disease for which they were carriers, and options available for prenatal diagnosis (PND).

\section{Carrier detection assays}

We developed molecular assays consisting of DNA amplification, followed by restriction enzyme analyses. The PCR conditions for the molecular assays were as follows: denaturation at $94^{\circ} \mathrm{C}$ for 5 minutes; 35 subsequent amplification cycles performed at $94^{\circ} \mathrm{C}$ for 15 seconds, at $55^{\circ} \mathrm{C}$ for 30 seconds, at $72^{\circ} \mathrm{C}$ for 10 seconds, and at $72^{\circ} \mathrm{C}$ for 5 minutes.

\section{Cerebrotendinous xanthomatosis}

We performed carrier detection by amplification of a $262 \mathrm{bp}$ fragment from genomic DNA, containing the causative mutation 355delC in exon 2 of the gene CYP27A1. ${ }^{17}$ The sense primer $5^{\prime}$-GCTTGGCCCAGTTATTCAGTTTTG-3', and the antisense primer 5' -GCCCTGTTCCAGTCCCTTCAG-3'.

The mutation revokes a restriction site for Fnu4H I restriction enzyme. We digested amplified fragments of DNA containing the mutation with Fnu4H I restriction enzyme and electrophoresed them on $8 \%$ acrylamide gels. Normal alleles showed 138 and 124 bp bands, heterozygous carriers showed 262, 138, and 124 bp bands, and homozygous-affected individuals showed $262 \mathrm{bp}$ fragments.

\section{Prolidase deficiency}

We performed carrier detection of the mutation c.605C $>$ T (S202F) in exon 8 of the gene PEPD by amplification of a 200 bp fragment from genomic DNA containing the mutation. The sense primer 5'-GTGCCTCCTGATAGTCACTGA-3', and the antisense primer $5^{\prime}$-TCATCCTCACG CAGTTCTCTC-3'.

The mutation introduces a new restriction site for Mbo II restriction enzyme. We digested amplified fragments of DNA containing the mutation with Mbo II restriction enzyme and electrophoresed them on $8 \%$ acrylamide gels. Normal alleles showed 173 and $27 \mathrm{bp}$ bands, heterozygous carriers showed $173,104,69$, and $27 \mathrm{bp}$ bands, and homozygous affected individuals showed 104, 69, and 27 bp fragments.

\section{Argininosuccinate lyase deficiency}

We performed carrier detection of the mutation c.346C $>$ T (Q116X) in exon 4 of the gene ASL by amplification of a $197 \mathrm{bp}$ fragment from genomic DNA containing the mutation. The sense primer $5^{\prime}$-TCACCTCCAGGAGCTCATTG- ${ }^{\prime}$, and the antisense primer $5^{\prime}$-AGGAGATGGTGCTCAGGGAG-3' .

The mutation introduces a new restriction site for Bfa I restriction enzyme. We amplified fragments of DNA containing the mutation with Bfa I restriction enzyme and electrophoresed them on $8 \%$ acrylamide gels. Normal alleles consisted of 197 bp bands; heterozygous carriers showed 197, 133, and 64 bp bands; and homozygous affected individuals showed 133 and 64 bp fragments.

\section{Carbamyl phosphate synthetase I deficiency}

We performed carrier detection of the mutation c.3265C $>$ T (R1089C) in exon 26 of the CPS1 gene by amplification of a 290 bp fragment from genomic DNA containing the mutation. The sense primer $5^{\prime}$-CCAATGGCTGATATTGTGAG-3', and the antisense primer 5'-AATATTCAGGTTGCAGCTCT-3'.

The mutation revokes a restriction site for Alw I restriction enzyme. We digested amplified fragments of DNA containing the mutation with Alw I restriction enzyme and electrophoresed them on $8 \%$ acrylamide gels. Normal alleles showed 160 and 130 bp bands, heterozygous carriers showed 290, 130, and 160 bp bands, and homozygous affected individuals showed $290 \mathrm{bp}$ fragments.

\section{RESULTS}

\section{Compliance for genetic counseling and testing}

Attendance at each group counseling session was 10-20 during the first phase (until May 2005) and 5-8 during the second phase (from June 2006). Many of the invitees of the second phase had been noncompliant in the first phase. The fact that most couples of child-bearing age were approached in the first phase further reduced the number invited in the second phase.

The attendees were predominantly women. At the end of the sessions, all attendees consented to genetic testing. The total number of individuals tested through December 2007 was 1425 . The nurses in the village assess this to be about $70 \%$ of the target population.

By December 2007, 58\% (125 individuals) of the spouses of identified carriers agreed to attend counseling sessions and perform genetic tests. Figure 3 presents the results of the screening program.

\section{Mutation identification}

We identified a novel mutation, c.3265C $>\mathrm{T}$ (R1089C), in the highly conserved and catalytically important exon 26 of the CPS1 gene in three individuals from the village.

\section{Carrier frequencies}

By December 2007 we identified 217 carriers for either one or two mutations. The carrier frequencies of CTX, PD, ASLD, and CPSD were 1:11, 1:21, 1:41, and 1:95, respectively. Twenty-one individuals were found carriers for both CTX and PD (Table 1).

\section{Detection of couples at risk}

During the screening program, 10 couples were identified at risk for having a child homozygous for one of the tested disorders. Of them, six are carriers for CTX, three for PD, and one for CPSD.

\section{Prenatal diagnosis and birth defect prevention}

Of the 10 couples detected as carriers, we know of seven pregnancies. All seven arrived at the prenatal clinic early enough in the pregnancy to be offered amniocentesis but not early enough to be offered chorionic villus sampling (CVS). Three agreed to amniocentesis, all of them carriers of CTX. Two of the fetuses tested homozygous for the causative mutation and one heterozygous. In all three cases, the parents decided to continue with the pregnancies. Parents of the two homozygotic newborns were counseled about treatment, and the newborns commenced with chenode- 


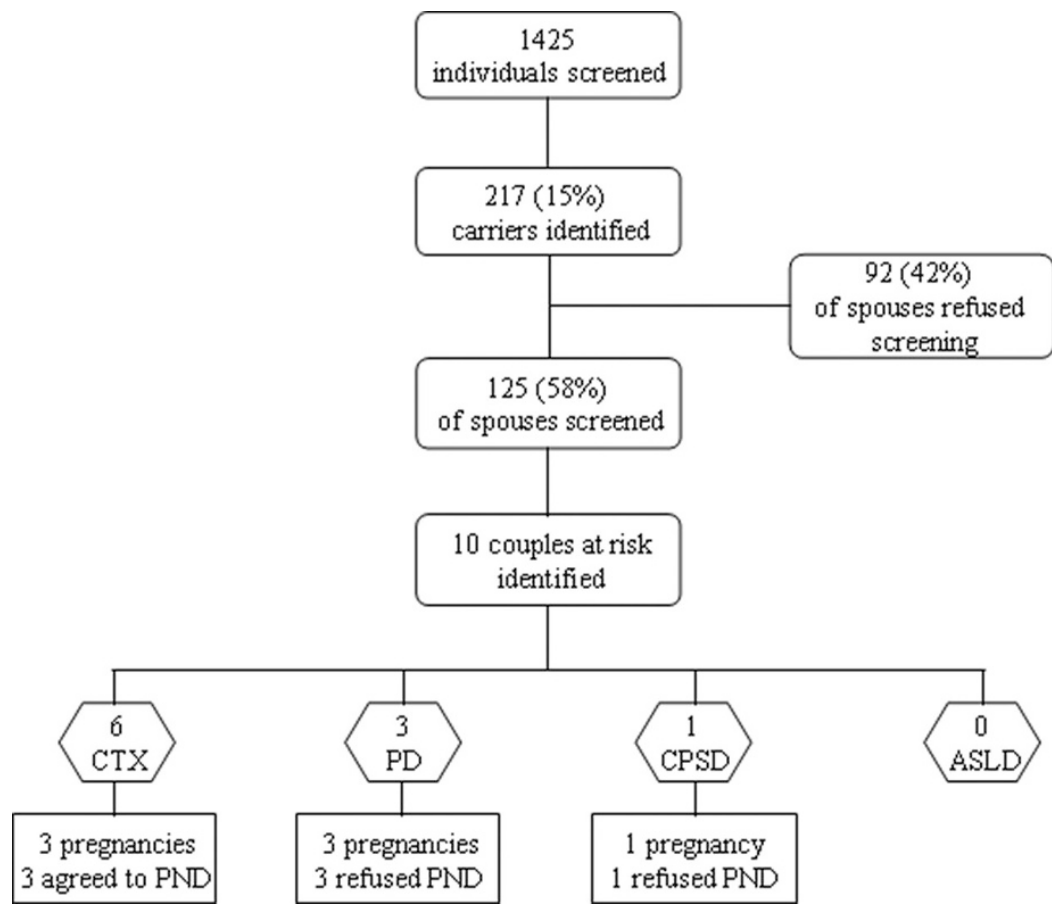

Fig. 3. Results of the screening program.

oxycholic acid (CDA) starting at the age of 1 month. This treatment has been recognized as effective for CTX. ${ }^{18,22}$

The four couples that refused PND did so on religious and social grounds, and also from physical fear of the test. Three were carriers of PD and one of CPSD. All the newborns of PD carriers were tested at birth. Two were homozygous for the wild allele. The third couple had fraternal twins; both were found carriers for the familial mutation. The CPSD carrier couple delivered a healthy baby, for whom genetic testing was not performed.

\section{DISCUSSION}

AR disorders are especially common in the Middle East ${ }^{23,24}$ and are associated with a unique spectrum of mutations of

Table 1

Carrier frequencies of the four disorders screened from 2003 to 2007

\begin{tabular}{|c|c|c|c|c|c|}
\hline Disorder & $\begin{array}{l}\text { No. screened } \\
\text { individuals }\end{array}$ & $\begin{array}{l}\text { Carriers } \\
\text { numbers }\end{array}$ & $\begin{array}{l}\text { Carrier } \\
\text { frequency }\end{array}$ & $\begin{array}{l}\text { General carrier frequency for one of the } \\
\text { four screened disorders in the village }\end{array}$ & $\begin{array}{l}\text { Worldwide carrier } \\
\text { frequency }\end{array}$ \\
\hline $\begin{array}{l}\text { Cerebrotendinous xanthomatosis } \\
\text { (CTX) }\end{array}$ & 1425 & 135 & $\sim 1: 11$ & $\sim 1: 6$ & $1: 115^{a}$ \\
\hline Prolidase deficiency (PD) & & 69 & $\sim 1: 21$ & & $\begin{array}{l}\text { Rare (no } \\
\quad \text { published data) }\end{array}$ \\
\hline Argininosuccinic aciduria (ASA) & 1134 & 28 & $\sim 1: 41$ & & $\begin{array}{l}\text { Rare (no } \\
\text { published data) }\end{array}$ \\
\hline $\begin{array}{l}\text { Carbamyl phosphate synthetase I } \\
\text { deficiency (CPSD) }\end{array}$ & & 12 & $\sim 95$ & & $\begin{array}{l}\text { Rare (no } \\
\text { published data) }\end{array}$ \\
\hline $\mathrm{CTX}+\mathrm{PD}$ & 1425 & 21 & $\sim 1: 68$ & & \\
\hline CTX + ASA & 1134 & 1 & & & \\
\hline CTX + CPSD & & 1 & & & \\
\hline $\mathrm{PD}+\mathrm{ASA}$ & & 1 & & & \\
\hline $\mathrm{PD}+\mathrm{CPSD}$ & & 1 & & & \\
\hline $\mathrm{ASA}+\mathrm{CPSD}$ & & 2 & & & \\
\hline
\end{tabular}

Total number of carriers detected, 217; total number of spouses tested, 125 ; response rate, $58 \%$.

${ }^{a}$ From Ref. 28. 
nonuniform distribution. ${ }^{25}$ The ensuing logistic and economic burden is high for affected families, local health care systems, and communities. ${ }^{26}$ However, preventative and consulting services are limited because of cultural, legal, political, financial, and religious issues. ${ }^{24,27}$ This reality presents challenges for genetic awareness and screening programs. To the best of our knowledge, this is the first study that reports general population genetic screening in a Druze community.

The genetic disorders we tested for, although rare worldwide, are relatively frequent in the described village, apparently due to founder novel mutations and a high rate of consanguinity. The carrier frequency for CTX, the most common disorder in this study, is $1: 11$, which is more than 10 times the highest reported previously. ${ }^{28}$ No published worldwide data are available to compare the carrier frequencies found for the other three disorders.

If the goal of population screening is reduction in the incidence and morbidity of inborn genetic disorders, true assessment is best after at least a generation of births. The Tay-Sachs screening program is informative. Over the course of 20 years, disease incidence dramatically decreased, ${ }^{9}$ exemplified by a $90 \%$ reduction in Montreal. ${ }^{10} \mathrm{~A}$ similar assessment of our program is difficult, not only due to its incipient stage but also to the number of challenges precipitating from the cultural and religious principles of the community:

1. The high, although decreasing, rate of consanguinity continually increases incidence rates of AR diseases. ${ }^{5-8}$ In the Druze community, however, reducing the number of first-cousin marriages may not significantly affect the number of birth defects, since in very inbred communities the risk of birth defects for couples that are first cousins is similar to that of those who are more distantly related. ${ }^{29}$

2. Lack of knowledge and apprehension of genetic counseling, fears of stigmatization, and the restrictions of a secretive religion, present obstacles to genetic counseling among the Druze. Not unexpectedly, only one third of the invitees attended the genetic counseling sessions, only $58 \%$ of spouses of women found to be carriers agreed to genetic testing, and only three of the couples at risk agreed to PND. None of the couples have terminated pregnancies. Of note, none of the women at risk reached a clinic at an early enough stage of their pregnancy to be offered CVS testing.

A screening program for Thalassemia implemented in the same village as our program provides a relevant comparison, with enlightening implications. During the years 1995-2007, 85 carrier couples were identified. Of the 179 times women were referred for genetic counseling (from a total of 213 pregnancies), 101 (56\%) and 35 (20\%) underwent CVS and amniocentesis, respectively. The percentages of women who terminated pregnancies subsequent to the detection of an affected embryo were $84 \%$ ( 21 of 25 ) and $15 \%$ (2 of 13) after CVS and amniocentesis, respectively. Supporting this data are a study that shows that both the severity of the disorder and the gesta- tion time at detection of the abnormality affect an Arab couple's decision to terminate pregnancy. ${ }^{30,31}$ The couples detected as carriers in our screening program reached clinics at a relatively late stage of their pregnancy and, therefore, were offered amniocentesis only and not CVS. Furthermore, the facts that CTX is a treatable disease, and PD is characterized by great, unpredicted phenotypic variability, complicated the genetic counseling and the decision-making process related to pregnancy management. ${ }^{19}$

The presence in most carrier families of both healthy and affected children as would be predicted according to AR inheritance, increases suspicion about birth defects. Furthermore, residents expressed the belief that affected children are "the will of God." Suspicion regarding birth defect prevention has been reported in other religious communities in Israel..$^{30,31}$

Considering the challenges inherent in a screening program in a Druze community, characterized by a secretive religion and endogamous culture, our program has made a number of achievements:

1. A large number of women attended educational sessions.

2. All of the attendees performed genetic testing at the end of the sessions.

3. Early detection of newborns affected with CTX enabled treatment, which prevented disease symptoms.

We attribute the success of our program to a number of factors. First, the implementation of population screening within the isolated village seems to have reduced stigmatization. This is in contrast to cascade screening in which only relatives of a proband are screened. The screening of all community members of childbearing age, regardless of their relation to an affected individual, has demonstrated effectiveness, while preserving the privacy imperative in closed communities.

Second, our sensitivity to the local culture is a high priority. This is manifested in our use of linguistically and culturally accessible materials, implementation of the program in the local prenatal clinic, assurance of confidentiality, sensitivity to stigmatization, flexibility regarding results reporting and counseling, and our full respect for couples' decisions regarding testing or terminating an affected pregnancy. From the inception of the program, we achieved high cooperation with local professionals, and with time we gradually gained the trust of the residents as well.

Drawbacks of the program are evident in the low turnout of spouses at the educational and testing sessions, and the fact that carrier couples did not arrive at prenatal clinics early enough during pregnancies to be offered CVS.

In time, it will be possible to calculate the impact of our screening program, including its cost effectiveness, on the prevention of genetic disorders and on the initiation of vital early treatment. We expect awareness of the importance of genetic counseling and evaluation, together with accessibility of the genetic counseling team, to increase interest in testing for other possible diseases and risk factors specific to couples' backgrounds and family history, such as recurrent abortions, cardiac anomalies, deafness, and mental retardation. 
Furthermore, our ongoing care of the residents of the village affords us the exceptional opportunity to follow the long-term health consequences of being a carrier for a defect in a major metabolic pathway. In the CPS1 group, for example, we are alert to the possibility of increased incidence of pulmonary hypertension or a pathologic condition involving compromised NO production. ${ }^{32}$ In the CTX group, the development of accelerated atherosclerosis, abnormal lipid profiles, and the dietary affect of cholestanol ${ }^{33}$ are matters for future follow up.

We conclude that genetic screening of endogamous populations at high risk for identified mutations should be a public concern. With time we will be able to assess if, by encouraging couples at childbearing age to use medical genetic services and modern genetic technology, we are planting seeds of empowerment, while minimizing pain and shame.

\section{ACKNOWLEDGMENTS}

We thank Prof. J. Zlotogora and Yasmin Levitatz from the Israeli Ministry of Health for supporting this program. We also thank the nurses from the prenatal clinics of the village: Stella Karayani, Hyam Reisha, Terese Gantus, and Bat Dora Barakart for their most significant contribution to the success of the screening program.

\section{References}

1. Shlush LI, Behar DM, Yudkovsky G, et al. The Druze: a population genetic refugium of the Near East. PloS ONE 2008;3:e2105.

2. Vardi-Saliternik R, Friedlander Y, Cohen T. Consanguinity in a population sample of Israeli Muslim Arabs, Christian Arabs, and Druze. Ann Hum Biol 2002;29:422431.

3. Cohen T, Vardi-Saliternik R, Friedlander Y. Consanguinity, intracommunity and intercommunity marriages in a population sample of Israeli Jews. Ann Hum Biol 2004;31:38-48.

4. Jaber L, Merlob P, Bu X, Rotter JI, Shohoat M. Marked parental consanguinity as a cause for increased major malformations in an Israeli Arab community. Am J Med Genet 1992;44:1-6.

5. Jaber L, Merlob P, Gabriel R, Shohat M. Effects of consanguineous marriage on reproductive outcome in an Arab community in Israel. J Med Genet 1997;34:1000 1002.

6. Stoll C, Alembik Y, Roth MP, Dott B. Parental consanguinity as a cause for increased incidence of birth defects in a study of 238,942 consecutive births. Ann Genet 1999; 42:133-139.

7. Zlotogora J. Research letter: what is the birth defect risk associated with consanguineous marriages? Am J Med Genet 2002;109:70-71.

8. Zlotogora J, Haklai Z, Rotem N, et al. Relative prevalence of malformations at birth among different religious communities in Israel. Am J Med Genet A 2003;122:5962.

9. Kaback M, Lim-Steele J, Dabholkar D, Brown D, Levy N, Zieger K. Tay-Sachs disease: carrier screening, prenatal diagnosis, and the molecular era. JAMA 1993;270: 2307-2315.

10. Mitchell JJ, Capua A, Clow C, Scriver CR. Twenty-year outcome analysis of genetic screening programs for tay-Sachs and B-Thalassemia disease carriers in high schools. Am J Hum Genet 1996;59:793-398.

11. Ostrowsky JT, Lippman A, Scriver CR. Cost-benefit analysis of a thalassemia disease prevention program. Am J Public Health 1985;75:732-736.

12. Khoury MJ, McCabe LL, McCabe ERT. Population screening in the age of genomic medicine. N Engl J Med 2003;348:50-58.

13. Pletcher BA, Gross SJ, Monaghan KG, Driscoll DA, Watson MS. The future is now: carrier screening for all populations. Genet Med 2008;10:33-36.

14. Shalev SA, Carmi R, Leventhal A, Zlotogora J. A comprehensive program for prevention of genetic disease among Arabs in Israel. Harefuah 2003;142:792-794.

15. Bach G, Zeigler M, Zlotogora M. Prevention of lysosomal storage disorders in Israel. Mol Genet Metab 2007;90:353-357.

16. Basel-Vanagaite L, Taub E, Halpern GJ, et al. Genetic screening for autosomal recessive nonsyndromic mental retardation in an isolated population in Israel. Eur J Hum Genet 2007;15:250-253.

17. Leitersdorf E, Safadi R, Meiner V, et al. Cerebrotendinous xanthomatosis in the Israeli Druze: molecular genetics and phenotypic characteristics. Am J Hum Genet 1994;55: 907-915.

18. Berginer VM, Gross B, Morad K, et al. Chronic diarrhea and juvenile cataracts: think cerebrotendinous xanthomatosis and treat. Pediatrics. In press.

19. Mandel H, Abeling N, Gutman A, et al. Prolidase deficiency among an Israeli population: prenatal diagnosis in a genetic disorder with uncertain prognosis. Prenat Diag 2000;20:927-929.

20. Hershkovitz T, Hassoun G, Indelman M, et al. A homozygous missense mutation in PEPD encoding peptidase D causes prolidase deficiency associated with hyper-IgE syndrome. Clin Exp Dermatol 2006;31:435-440.

21. Linnebank M, Tschiedel E, Haberle J, et al. Arginiosuccinate lyase (ASL) deficiency: mutation analysis in 27 patients and a completed structure of the human ASL gene. Hum Genet 2002;111:350-359.

22. Salen G, Meriwether TW, Nicolau G. Chenodeoxycholic acid inhibits increased cholesterol and cholestanol synthesis in cerebrotendinous xanthomatosis. Biochem Med 1975;14:57-74.

23. Zlotogora J, Shalev S, Habiballah H, Barjes S. Genetic disorders among Palestinian Arabs: 3. Autosomal recessive disorders in a single village. Am J Med Genet 2000;92: 343-345.

24. Al-Gazali L, Hamamy H, Al-Arrayad S. Genetic disorders in the Arab world. BMJ 2006;333:831-834.

25. Zlotogora J, van Baal S, Patrinos GP. Documentation of inherited disorders and mutation frequencies in the different religious communities in Israel in the Israeli National Genetic Database. Human Mutat 2007;28:944-949.

26. Alwan A, Modell B. Recommendations for introducing genetics services in developing countries. Nat Rev Genet 2003;4:61-68.

27. Saadallah AA, Rashed MS. Newborn screening: experiences in the Middle East and North Africa. J Inherit Metab Dis 2007;30:482-489.

28. Lorincz MT, Rainier S, Thomas D, Fink JK. Cerebrotendinous xanthomatosis: possible higher prevalence than previously recognized. Arc Neurol 2005;62:1459-1463.

29. Zlotogora J. Research letter: is there an increased birth defect risk to children born to offspring of first cousin parents? Am J Med Genet 2005;137A:342.

30. Zlotogora J. Parental decisions to abort or continue a pregnancy with an abnormal finding after an invasive prenatal test. Prenat Diagn 2002;22:1102-1106.

31. Sher C, Romano-Zelekha O, Green MS, Shohat T. Utilization of prenatal genetic testing by Israeli Moslem women: a national survey. Clin Genet 2004;65:278-283.

32. Canter JA, Summar ML, Smith HB, et al. Genetic variation in the mitochondrial enzyme carbamyl-phosphate synthetase I predisposes children to increased pulmonary artery pressure following surgical repair of congenital heart defects: a validated genetic association study. Mitochondrion 2007;7:204-210.

33. Seyama Y. Cholestanol metabolism, molecular pathology, and nutritional implications. J Med Food 2003;6:217-224. 